\title{
Silencing suppressors: viral weapons for countering host cell defenses
}

\author{
Liping Song $^{1 *}$, Shijuan Gao ${ }^{1 *}$, Wei Jiang ${ }^{1}$, Shuai Chen ${ }^{1}$, Yanjun Liu $^{3}$, Ling Zhou ${ }^{3}$, Wenlin Huang ${ }^{1,2} \bowtie$ \\ ${ }^{1}$ CAS Key Laboratory of Pathogens and Immunology, Institute of Microbiology, Chinese Academy of Sciences, Beijing 100101, \\ China \\ 2 State Key Laboratory of Oncology in South China, Cancer Center, Sun Yat-sen University, Guangzhou 510060, China \\ 3 The 306th Hospital of Chinese PLA, China \\ $\triangle$ Correspondence: hwenl@mail.sysu.edu.cn \\ Received March 9, 2011 Accepted March 30, 2011
}

\begin{abstract}
RNA silencing is a conserved eukaryotic pathway involved in the suppression of gene expression via sequence-specific interactions that are mediated by 21-23 nt RNA molecules. During infection, RNAi can act as an innate immune system to defend against viruses. As a counter-defensive strategy, silencing suppressors are encoded by viruses to inhibit various stages of the silencing process. These suppressors are diverse in sequence and structure and act via different mechanisms. In this review, we discuss whether RNAi is a defensive strategy in mammalian host cells and whether silencing suppressors can be encoded by mammalian viruses. We also review the modes of action proposed for some silencing suppressors.
\end{abstract}

KEYWORDS RNA interference (RNAi), silencing suppressors, mammalian virus

\section{INTRODUCTION}

RNA interference (RNAi), also called RNA silencing, is a conserved eukaryotic pathway involved in suppression of gene expression via sequence-specific interactions that are mediated by small-interfering RNAs (siRNAs), which are 21-23 nt in length and are derived from exogenous doublestranded RNA (dsRNA) or endogenous microRNA (miRNA) (Ruiz et al., 1998; Zamore et al., 2000; Bernstein et al., 2001; Huang et al., 2007). In addition to its diverse biological functions, RNAi has recently emerged as an important antiviral mechanism in host cells (Coleman, 2007; van Rij, 2008). It was first discovered in plants that RNAi provides an antiviral mechanism by which viral dsRNAs are cleaved by the ribonuclease Dicer to generate viral siRNAs. These siRNAs are then incorporated into the RNA-induced silencing complex (RISC) and direct RISC activity to messenger RNAs (mRNAs) in a sequence-specific manner (Ding and Voinnet, 2007; Ding, 2010; Olivieri et al., 2010; Reyes et al., 2011). Complementary sequences in the viral mRNA can be targeted by the viral siRNAs for endonucleic cleavage or translational inhibition, which represses viral replication.

Whether RNAi has natural antiviral activity in mammals is a hotly debated issue. Two main points have been put forward by those who do not think that RNAi has natural antiviral activity in mammals. The first is that virus-derived siRNAs cannot be detected by small-RNA cloning in tissue-culture models for the hepatitis $C$ virus (HCV) and yellow fever virus (Pfeffer et al., 2005). Although a single specific viral-derived siRNA corresponding to the structured Rev responsive element has been detected in human immunodeficiency virus-1 (HIV-1) infected cells (Bennasser et al., 2005), this observation could not be reproduced by another laboratory (Lin and Cullen, 2007). The second reason is that many viruses, such as influenza $A$ virus and vaccinia virus, replicated to similar, or even lower, viral titers in Dicer $^{-/}$ macrophages (Otsuka et al., 2007). On the other hand, although whether viruses encode miRNAs during the infection process has been controversial, increasing evidence suggests that miRNAs which are encoded by host cells can regulate the replication of the virus. Song et al. reported that host miR-323, miR-491 and miR-654 inhibit the replication of the H1N1

"These authors contributed equally to the work. 
influenza virus in MDCK cells by binding and degrading PB1 (a subunit of influenza virus RNA polymerase) (Song et al., 2010). Otsuka et al. have reported that host miR-24 and miR93 can target viral large protein and phosphoprotein genes, and that a lack of miR-24 and miR-93 is responsible for increased vesicular stomatitis virus (VSV) replication (Otsuka et al., 2007). These data suggest that RNAi is probably part of the innate immune system in mammals.

Since RNAi is an important antiviral pathway in host cells in plants, as a counter-defensive strategy, many viruses encode silencing suppressors, a kind of protein which can suppress RNA silencing at different stages of the process (Moissiard and Voinnet, 2004). The first hint that viruses encode silencing suppressors came from seminal experiments aimed at understanding the phenomenon of synergism (Vance, 1991). In 1997, the potyviral helper component proteinase (Hc-Pro) was first identified as a silencing suppressor. With further research, an increasing number of silencing suppressors have been identified in plant viruses and also in mammalian viruses, which indicates silencing suppressors as a host counter defensive mechanism widely adopted by different viruses. In this review, we will discuss a few examples of silencing suppressors and the molecular basis of their function.

\section{SILENCING SUPPRESSORS ENCODED BY PLANT VIRUSES}

In plants, RNA silencing forms the basis of an elaborate immune system that is activated by, and targeted against, viruses. As a counter-defensive strategy, viruses have evolved suppressor proteins that inhibit various stages of the silencing process (Table 1). These suppressors are diverse in sequence and structure.

\section{HC-Pro}

The first silencing suppressor discovered is potyvirusencoded helper component-proteinase (HC-Pro) which enhances the replication of many unrelated viruses (Kasschau et al., 1997; Pruss et al., 1997). Tobacco etch virus silencing suppressor is comprised of the 5'-proximal region of the tobacco etch potyviral genomic RNA encoding $\mathrm{P} 1, \mathrm{HC}$-Pro and a small part of $\mathrm{P} 3$, and is termed $\mathrm{P} 1 / \mathrm{HC}-\mathrm{Pro}$. $\mathrm{P} 1 / \mathrm{HC}-\mathrm{Pro}$ can suppress virus-induced posttranscriptional gene silencing and further assessment of the function of P1/ $\mathrm{HC}$-Pro showed that expression of the HC-Pro coding sequence alone is sufficient to suppress virus-induced gene silencing, and that the HC-Pro protein product is required for suppression (Anandalakshmi et al., 1998; Brigneti et al., 1998; Kasschau and Carrington, 1998). As HC-Pro is a pathogenicity determinant and is involved in other viral functions such as polyprotein processing, it is speculated that silencing suppressors play other roles in addition to suppressing RNAi.

\section{P19}

Another well-characterized suppressor is the tombusvirusencoded P19 protein. P19, which is highly conserved and expressed in many different tombusvirus species, was first identified as a silencing suppressor in 1999 (Voinnet et al., 1999). P19 suppresses RNAi in plants and blocks RNAi by binding siRNA via its dsRNA-binding domain. High dosages of $\mathrm{P} 19$ are essential for viral pathogenicity. Since siRNAs are universally involved in RNA-silencing, these findings predict that P19 should be effective in a broad range of organisms. Dunoyer et al. reported that P19 can bind siRNA and suppress RNAi in HeLa cells, suggesting that this factor may be useful for dissecting the RNA silencing pathway in animals (Dunoyer et al., 2004).

\section{DO MAMMALIAN VIRUSES ENCODE SILENCING SUPPRESSORS?}

It has been clearly demonstrated that plant viruses encode silencing suppressors during infection. However, whether mammalian viruses encode silencing suppressors has been controversial. Kok and Jin reported that the influenza A virus non-structural (NS1) protein does not suppress RNA interference in mammalian cells (Kok and Jin, 2006). On the other hand, Haasnoot et al. have reported that NS1 can act as a silencing suppressor in Vero cells which lack the interferon (IFN) pathway. Their results suggest that certain cellular factors involved in IFN pathway may effect the silencing suppressor activity of NS1 in mammalian cells (Haasnoot et al., 2007). In addition, Bennasser et al. reported that HIV-1 evades elicited RNAi through a suppressor of RNA silencing (SRS) function encoded in its Tat protein; Tat suppresses an otherwise effective RNAi restriction through functional abrogation of the cell's Dicer activity (Bennasser et al., 2005). However, Lin reported that neither HIV-1 nor human T-cell leukemia virus type 1(HTLV-1) expresses significant levels of either small interfering RNAs or microRNAs in persistently infected T cells (Lin and Cullen, 2007). The author also demonstrates that the retroviral nuclear transcription factors HIV-1 Tat and HTLV-1 Tax, as well as the Tas transactivator encoded by the primate foamy virus, fail to inhibit RNA interference in human cells.

Although whether silencing suppressors are encoded by mammalian viruses has been controversial, increasing evidence shows that mammalian viruses should encode silencing suppressors to counter the defense system of host cells. Many miRNAs have been found to play very important functions in inhibiting the replication of viruses. We would expect that, in line with typical interactions between viruses and their hosts, silencing suppressors should be encoded by mammalian viruses to counter host responses.

But why has this debate lasted such a long time? It may be because, first, in mammalian cells, the main antiviral mechanism involves both the IFN pathway and the $2^{\prime}-5^{\prime}$ 

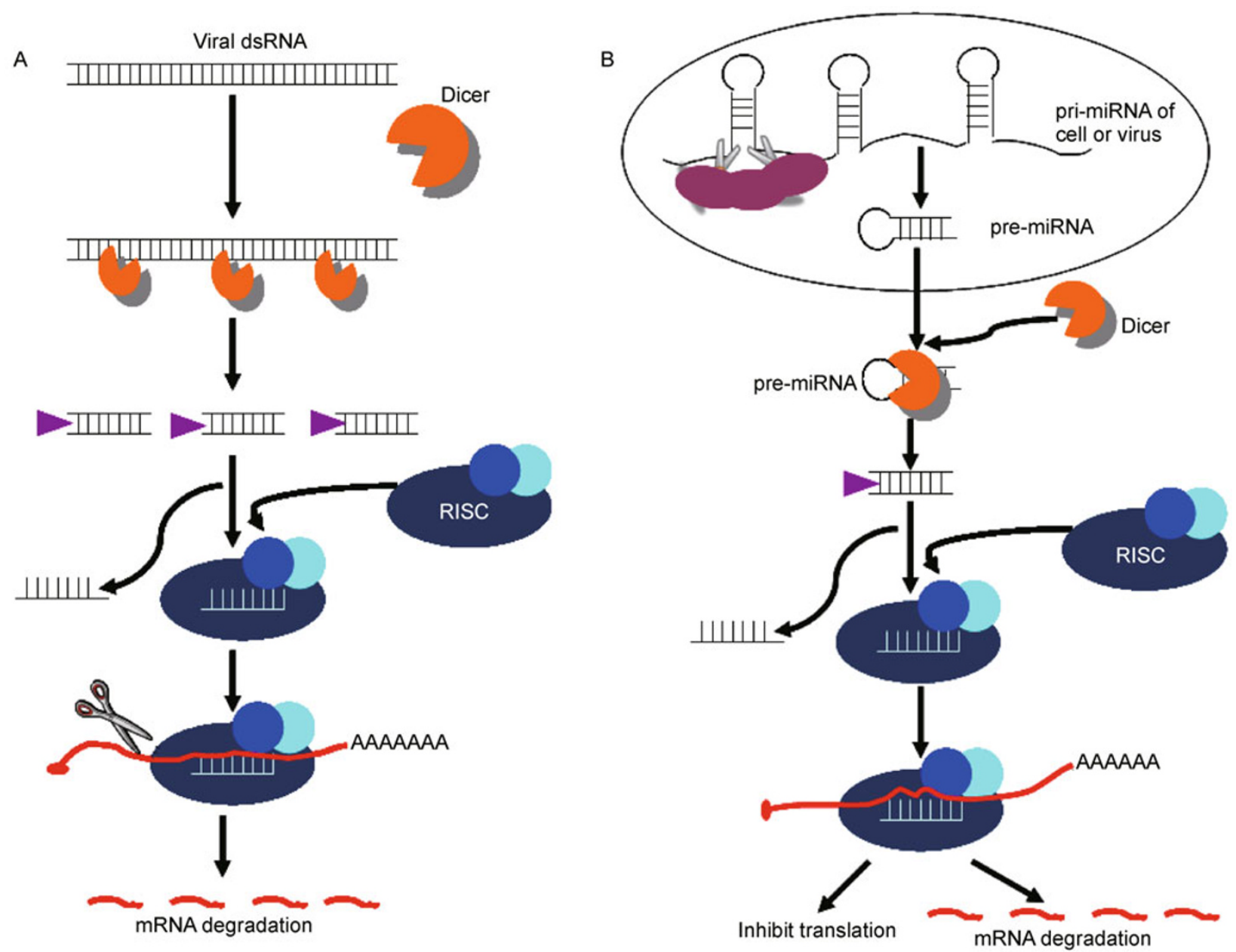

Figure 1. RNA silencing during virus infection in plant and mammalian cells. (A) RNA interference (RNAi) is an antiviral defense mechanism in plant. Viral dsRNA cleaved by the ribonuclease Dicer generates viral siRNAs that are processed by the RNAi machinery and program the RNA-induced silencing complex (RISC) to degrade viral RNAs. (B) When mammalian cells are infected by viruses, host cells and the virus may encode miRNAs which can be loaded in the RISC to degrade the target gene.

oligoadenylate cyclase (2'-5' OAS)/RNAseL/PKR pathway. Whether miRNA is an antiviral pathway is still unclear; second, that NS1 only acts as a silencing suppressor in IFN-lacking cells suggests that the function of silencing suppressors may be determined by certain cellular factors; third, since the defense system of mammalian cells is very intricate, when mammalian viruses infect host cells, several proteins may work together as a silencing suppression complex during infection.

\section{SILENCING SUPPRESSORS ENCODED BY MAMMALIAN VIRUSES}

At present, only a few silencing suppressors encoded by mammalian viruses have been identified. These silencing suppressors have many common characteristics. First, silencing suppressors have IFN/PKR antagonistic properties which are related to the pathogenicity of the virus. Second, most silencing suppressors have dsRNA binding domains and can bind to dsRNA or siRNA. Finally, silencing suppressors are multi-functional proteins during the infection process.

\section{Tat protein of HIV-1}

HIV-1 Tat is a multi-functional protein (El Kharroubi et al., 1998; Isel and Karn, 1999; Liu et al., 2002; Epie et al., 2005). In infected cells, Tat not only increases initiation of HIV-1 transcription but can also help to maintain the transcription process (Herrmann and Rice, 1995; Yang et al., 1997; Kiernan et al., 1999).

In addition to its function in HIV-1 transcription, Tat may contribute to HIV-1 pathogenesis by regulating signal transduction in endothelial cells, functioning as a secreted growth factor for Kaposisarcoma and endothelial cells (Cantaluppi et al., 2001; Rusnati and Presta, 2002), and 
Table 1 Silencing supp ressors encoded by plant viruses

\begin{tabular}{|c|c|c|c|c|}
\hline $\begin{array}{l}\text { Silencing } \\
\text { suppressor }\end{array}$ & Virus species and group & Genome & Mode of action & References \\
\hline P19 & TBSV (Tombusvirus) & RNA(+) & siRNA binding & Voinnet et al., 1999 \\
\hline Hc-Pro & TuMV, PVY, TEV (Potyvirus) & $\mathrm{RNA}(+)$ & $\begin{array}{l}\text { Prevents accumulation } \\
\text { of siRNA }\end{array}$ & $\begin{array}{l}\text { Anandalakshmi et al., 1998; Brigneti et al., } \\
\text { 1998; Kasschau and Carrington, } 1998\end{array}$ \\
\hline $\mathrm{P} 1$ & RYMV (Sobemovirus) & $\mathrm{RNA}(+)$ & ? & Voinnet et al., 1999 \\
\hline P0 & BWYV (Luteovirus) & $\mathrm{RNA}(+)$ & $?$ & Pfeffer et al., 2002 \\
\hline $2 b$ & CMV (Cucumovirus) & $\mathrm{RNA}(+)$ & Nuclear localization & Brigneti et al., 1998 \\
\hline $\begin{array}{l}\mathrm{P} 21, \mathrm{P} 20 \\
\mathrm{P} 23, \mathrm{CP}\end{array}$ & BYV, CTV (Closterovirus) & $\mathrm{RNA}(+)$ & $?$ & Reed et al., 2003; Lu et al., 2004 \\
\hline $\mathrm{AC} 2, \mathrm{C} 2$ & $\begin{array}{l}\text { MYMV, ACMV, TYLCV } \\
\text { (Geminivirus) }\end{array}$ & DNA & DNA binding (Zn finger) & Voinnet et al., 1999; van et al., 2002 \\
\hline $\mathrm{P} 15$ & PCV (Pecluvirus) & $\mathrm{RNA}(+)$ & Protein-protein interaction & Voinnet et al., 1999; Dunoyer et al., 2002 \\
\hline P38 & TCV (Carmovirus) & $\mathrm{RNA}(+)$ & ? & Thomas et al., 2003; Qu et al., 2003 \\
\hline $\mathrm{P} 25$ & PVX (Potexvirus) & $\mathrm{RNA}(+)$ & $?$ & Voinnet et al., 2000 \\
\hline NSs & TSWV (Tospovirus) & RNA(-) & $?$ & Takeda et al., 2002; Bucher et al., 2003 \\
\hline NS3 & RHBV (Tenuivirus) & RNA(-) & ? & Bucher et al., 2003 \\
\hline $\mathrm{yb}$ & BSMV (Hordeivirus) & $\mathrm{RNA}(+)$ & $?$ & Yelina et al., 2002; Bucher et al., 2003 \\
\hline B2 & FHV, NoV (Nodavirus) & $\mathrm{RNA}(+)$ & $?$ & Li et al., 2002 \\
\hline PBO & ToMV (Tobamovirus) & $\mathrm{RNA}(+)$ & $?$ & Kubota et al., 2002 \\
\hline S protein & CPMV (Comovirus) & $\mathrm{RNA}(+)$ & $?$ & Liu et al., 2004 \\
\hline P30 & TMV (Tobamovirus) & $\mathrm{RNA}(+)$ & $?$ & Kubota et al., 2003 \\
\hline P69 & TYMV (Tymovirus) & $\mathrm{RNA}(+)$ & $?$ & Chen et al., 2004 \\
\hline
\end{tabular}

inducing apoptosis in T-cells by binding to microtubules and delaying tubulin depolymerization (Nath et al., 1996; Chen et al., 2002). In 2005, Bennasser el al. reported that HIV encodes viral siRNA precursors in its genome and that natural HIV-1 infection provokes nucleic acid-based immunity in human cells. To combat this cellular defense, HIV has evolved a suppressor of RNA silencing function in its Tat protein. Their results show that Tat plays its silencing suppressor function by inhibiting Dicer activity and that its silencing suppressor activity is distinct from its transcriptional function (Bennasser et al., 2005).

\section{VP35 of the Ebola virus}

VP35, an ebolavirus protein, plays a key role in the interaction of the virus with its target cells (Hartman et al., 2004). VP35 is required for viral replication and transcription and antagonizes the host cell type I IFN system during viral infection (Mühlberger et al., 1999; Basler et al., 2000). Haasnoot et al. reported that VP35 is a silencing suppressor in mammalian cells and that its RNA silencing suppressor (RSS) activity is functionally equivalent to that of the HIV-1 Tat protein. The VP35 dsRNA-binding domain is required for this silencing suppressor activity (Haasnoot et al., 2007).

\section{The non-structural protein of influenza A virus}

Since the non-structural (NS1) protein of influenza A virus, like the silencing suppressors encoded by mammalian viruses described above, possesses IFN or protein kinase $\mathrm{R}(\mathrm{PKR})$ antagonistic properties, we speculated that it is a silencing suppressor during viral infection. The NS1 protein of influenza $A$ viruses is a non-essential virulence factor that has multiple accessory functions during viral infection. It has been demonstrated that the NS1 protein has silencing suppressor activity in insect and plant cells (Bucher et al., 2004; Delgadillo et al., 2004; Li et al., 2004). However, the silencing suppressor activity of NS1 in mammalian cells was not observed until 2007; results showed that NS1 protein is able to suppress RNAi in Vero (IFN ${ }^{-}$) cells but not in HEK293T (IFN ${ }^{+}$) cells (Haasnoot et al., 2007). Haasnoot et al. suggest that NS1 is able to suppress short hairpin RNA (shRNA)induced RNAi in mammalian cells, and that the cell typedependent silencing suppressor activity of NS1 is related to the expression level of certain cellular RNAi co-factors.

\section{Vaccinia virus E3L (E3L)}

Vaccinia virus, a member of the Orthopoxviridae, contains a 
large double-stranded DNA genome carrying approximately 190 genes (Langland et al., 2006). The vaccinia virus E3L gene is an essential virulence gene that confers IFN resistance in cell culture of a broad range of hosts (Beattie et al., 1996; Langland and Jacobs, 2002). The E3L gene encodes a 190-amino-acid protein with a highly conserved, carboxyl-terminal, double-stranded RNA (dsRNA)-binding domain (Chang and Jacobs, 1993; Saunders and Barber, 2003). The dsRNA-binding domain has been shown to be required for both IFN resistance and broad-host-range phenotypes associated with the vaccinia virus (Chang et al., 1995). In addition to the above-mentioned function of E3L, $\mathrm{Li}$ et al. reported that E3L can block induced RNAi against reporter gene constructs. Moreover, $\mathrm{E} 3 \mathrm{~L}$ is able to replace the RNAi suppression function of the b2 protein encoded by the Flock house virus and to support virus replication in insect cells (Li et al., 2004). The mechanism of the RNAi suppression function of $\mathrm{E} 3 \mathrm{~L}$ is still not clear.

\section{Hepatitis C virus core}

The core protein is the first synthesized protein during the early phases of $\mathrm{HCV}$ infection. It can influence cellular immunity, cell growth, apoptosis, cell transformation, and eventually tumor development (hepatocellular carcinoma and possibly B cell lymphoma) (Basu et al., 2001). Wang et al. reported that the HCV core protein is able to counteract the RNA-silencing response through a direct interaction with Dicer. This ability of the core protein to counter host defenses may contribute to the establishment of persistent HCV infections (Wang et al., 2006).

\section{Primate foamy virus type 1 (PFV-1) Tas}

Lecellier et al. reported that cellular microRNA effectively restricts the accumulation of PFV-1 in human cells (Lecellier et al., 2005). To counter the defense system of the host cell, PFV-1 encodes a viral transactivator, Tas, which acts as a silencing suppressor during infection. Like several plant viral suppressors, Tas can promote the nonspecific over-accumulation of cellular miRNAs (Kasschau et al., 2003; Dunoyer et al., 2004). Tas also shows silencing suppression activity in a heterologous system.

\section{THE MOLECULAR BASIS OF SILENCING SUPPRESSION}

At present, research on the action mechanism of silencing suppression is just beginning. Here we review the modes of action of these silencing suppressors (Fig. 2). (1) Silencing suppressor can inhibit the key components of RNA-silencing pathways, as highlighted by the function of the tombusviral P19 protein. In vitro, P19 binds PTGS (posttranscriptional gene silencing)-generated, 21-25 nt dsRNAs and $21 \mathrm{nt}$ synthetic dsRNA with 2-nt 3 ' overhanging end(s), while it barely interacts with single stranded (ss) RNAs, long dsRNAs or blunt-ended 21-nt dsRNAs. Silhavy et al. propose that P19 mediates silencing suppression by sequestering PTGSgenerated 21-25 nt dsRNAs (Silhavy et al., 2002). P19 also binds to classes of small RNAs in vivo and P19-mediated sequestration of siRNA in virus-infected cells blocks the spread of the mobile, systemic signal of RNA silencing (Lakatos et al., 2004). The mechanism by which P19 selectively recognizes the siRNA silencing signal was unknown until 2003 when Vargason et al. presented the crystal structure of the Carnation Italian Ringspot Virus (CIRV) P19 protein in complex with a $21 \mathrm{nt}$ siRNA. The results showed that the CIRV P19 protein acts as a molecular caliper to specifically select siRNAs based on the length of the duplex region of the RNA. In addition to binding to the siRNA to inhibit the RNAi pathway, some silencing suppressors such as HIV-1 Tat and hepatitis $C$ virus core protein can suppress the RNAi pathway by inhibiting Dicer activity. (2) A second silencing-suppression strategy involves the recruitment of endogenous negative regulators of RNA silencing. For example, yeast two-hybrid system results show that HC-Pro can interact with calmodulin-related protein (termed rgs$\mathrm{CaM}$ ), another cellular suppressor of PTGS (Anandalakshmi et al., 2000). (3) Some silencing suppressors function by interacting with molecules from host cell. For example, geminivirus transcriptional-activator proteins (TrAPs, also known as AL2, AC2, or C2 protein) have been identified as silencing suppressors. It has been reported that TrAPs from tomato golden mosaic virus (TGMV) bind zinc and that zinc is necessary for their optimal interaction with single-stranded DNA. The nuclear localization and zinc- and DNA-binding activities of TrAPs are all required for their suppressor function, indicating that they are involved in the function of TrAPs at the host-DNA level (Hartitz et al., 1999; van et al., 2002; Van Wezel et al., 2003). VP35 can bind to dsRNA and this dsRNA binding capacity is required for its silencing suppressor activity. These results suggest that VP35mediated RNAi suppression and VP35-dsRNA-dependent IFN antagonistic properties are linked. Haasnoot et al. proposed that VP35 is able to sequester virus-specific siRNA or dsRNA precursors of siRNA, resulting in suppression of an antiviral RNAi response that acts upstream of the 2'-5' OAS/RNAseL/PKR and IFN pathway (Haasnoot et al., 2007).

\section{CONCLUSION AND FUTURE DIRECTIONS}

Our understanding of silencing suppressor has considerably improved over the past few years. This research has also promoted the emergence of new and important concepts, such as that RNAi is a part of the native immunity system and that many viruses can encode negative regulators of RNA silencing and achieve successful replication in host cells. 

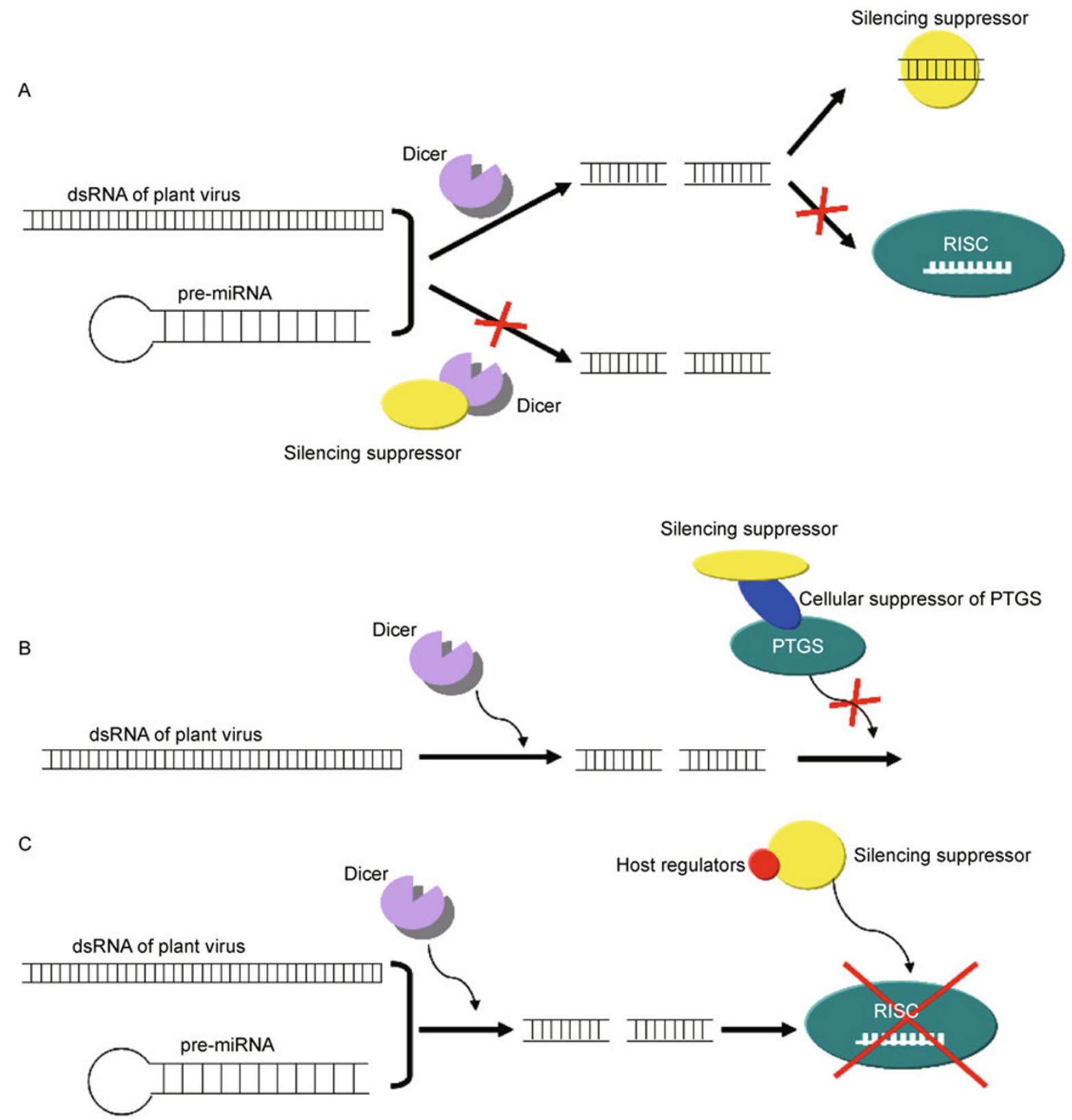

Figure 2. The molecular mechanism of silencing suppression. (A) Silencing suppressors can inhibit the key components of RNA-silencing pathways. (B) Silencing suppressors can recruit endogenous negative regulators of RNA silencing. (C) Some silencing suppressors act by interacting with molecules from host cells.

Mechanisms of silencing suppressors encoded by plant viruses are becoming clearer; however, the mechanisms of silencing suppressors encoded by mammalian viruses still require further research. The major challenge for the future will be to fully determine the extent to which RNA silencing is integrated within the interlinked and numerous layers of innate host defenses, such as the IFN pathway, and to understand the impact of silencing suppression on these pathways. In any case, it is anticipated that immune systems that are based on small RNAs either of pathogenic or cellular origin, are likely to be widespread.

\section{ACKNOWLEDGEMENTS}

This work was supported by grants from the National Basic Research Program (973 Project) (Grant No. 2011CB504805). Support was also 
provided by the National Natural Science Foundation of China (Grant No. 30900759/C0709) and the Postdoctoral Foundation of China.

\section{ABBREVIATIONS}

HC-Pro, potyvirus-encoded helper component-proteinase; HCV, hepatitis $C$ virus; HTLV-1, human T-cell leukemia virus type 1; IFN, interferon; mRNAs, messenger RNAs; miRNA, microRNA; NS1, nonstructural protein of influenza A virus; PFV-1, primate foamy virus type 1; RISC, RNA-induced silencing complex; RNAi, RNA interference; RSS, RNA silencing suppressor; shRNA, short hairpin RNA; siRNAs, small-interfering RNAs; SRS, suppressor of RNA silencing; VSV, vesicular stomatitis virus

\section{REFERENCES}

Anandalakshmi, R., Marathe, R., Ge, X., Herr, J.M. Jr, Mau, C., Mallory, A., Pruss, G., Bowman, L., and Vance, V.B. (2000). A calmodulin-related protein that suppresses posttranscriptional gene silencing in plants. Science 290, 142-144.

Anandalakshmi, R., Pruss, G.J., Ge, X., Marathe, R., Mallory, A.C., Smith, T.H., and Vance, V.B. (1998). A viral suppressor of gene silencing in plants. Proc Natl Acad Sci U S A 95, 13079-13084.

Basler, C.F., Wang, X., Mühlberger, E., Volchkov, V., Paragas, J., Klenk, H.D., García-Sastre, A., and Palese, P. (2000). The Ebola virus VP35 protein functions as a type I IFN antagonist. Proc Natl Acad Sci U S A 97, 12289-12294.

Basu, A., Meyer, K., Ray, R.B., and Ray, R. (2001). Hepatitis C virus core protein modulates the interferon-induced transacting factors of Jak/Stat signaling pathway but does not affect the activation of downstream IRF-1 or 561 gene. Virology 288, 379-390.

Beattie, E., Kauffman, E.B., Martinez, H., Perkus, M.E., Jacobs, B.L., Paoletti, E., and Tartaglia, J. (1996). Host-range restriction of vaccinia virus E3L-specific deletion mutants. Virus Genes 12, 89-94.

Bennasser, Y., Le, S.Y., Benkirane, M., and Jeang, K.T. (2005). Evidence that HIV-1 encodes an siRNA and a suppressor of RNA silencing. Immunity 22, 607-619.

Bernstein, E., Caudy, A.A., Hammond, S.M., and Hannon, G.J. (2001). Role for a bidentate ribonuclease in the initiation step of RNA interference. Nature 409, 363-366.

Brigneti, G., Voinnet, O., Li, W.X., Ji, L.H., Ding, S.W., and Baulcombe, D.C. (1998). Viral pathogenicity determinants are suppressors of transgene silencing in Nicotiana benthamiana. EMBO J 17, 6739-6746.

Bucher, E., Hemmes, H., de Haan, P., Goldbach, R., and Prins, M. (2004). The influenza A virus NS1 protein binds small interfering RNAs and suppresses RNA silencing in plants. J Gen Virol 85, 983-991.

Bucher, E., Sijen, T., De Haan, P., Goldbach, R., and Prins, M. (2003). Negative-strand tospoviruses and tenuiviruses carry a gene for a suppressor of gene silencing at analogous genomic positions. J Virol 77, 1329-1336.

Cantaluppi, V., Biancone, L., Boccellino, M., Doublier, S., Benelli, R., Carlone, S., Albini, A., and Camussi, G. (2001). HIV type 1 Tat protein is a survival factor for Kaposi's sarcoma and endothelial cells. AIDS Res Hum Retroviruses 17, 965-976.

Chang, H.W., and Jacobs, B.L. (1993). Identification of a conserved motif that is necessary for binding of the vaccinia virus E3L gene products to double-stranded RNA. Virology 194, 537-547.

Chang, H.W., Uribe, L.H., and Jacobs, B.L. (1995). Rescue of vaccinia virus lacking the E3L gene by mutants of E3L. J Virol 69, 6605-6608.

Chen, D., Wang, M., Zhou, S., and Zhou, Q. (2002). HIV-1 Tat targets microtubules to induce apoptosis, a process promoted by the proapoptotic Bcl-2 relative Bim. EMBO J 21, 6801-6810.

Chen, J., Li, W.X., Xie, D., Peng, J.R., and Ding, S.W. (2004). Viral virulence protein suppresses RNA silencing-mediated defense but upregulates the role of microrna in host gene expression. Plant Cell 16, 1302-1313.

Coleman, J.R. (2007). The PB1-F2 protein of Influenza A virus: increasing pathogenicity by disrupting alveolar macrophages. Virol J 4, 9.

Delgadillo, M.O., Sáenz, P., Salvador, B., García, J.A., and SimónMateo, C. (2004). Human influenza virus NS1 protein enhances viral pathogenicity and acts as an RNA silencing suppressor in plants. J Gen Virol 85, 993-999.

Ding, S.W. (2010). RNA-based antiviral immunity. Nat Rev Immunol 10, 632-644.

Ding, S.W., and Voinnet, O. (2007). Antiviral immunity directed by small RNAs. Cell 130, 413-426.

Dunoyer, P., Lecellier, C.H., Parizotto, E.A., Himber, C., and Voinnet, O. (2004). Probing the microRNA and small interfering RNA pathways with virus-encoded suppressors of RNA silencing. Plant Cell 16, 1235-1250.

Dunoyer, P., Pfeffer, S., Fritsch, C., Hemmer, O., Voinnet, O., and Richards, K.E. (2002). Identification, subcellular localization and some properties of a cysteine-rich suppressor of gene silencing encoded by peanut clump virus. Plant J 29, 555-567.

El Kharroubi, A., Piras, G., Zensen, R., and Martin, M.A. (1998). Transcriptional activation of the integrated chromatin-associated human immunodeficiency virus type 1 promoter. Mol Cell Biol 18, 2535-2544.

Epie, N., Ammosova, T., Sapir, T., Voloshin, Y., Lane, W.S., Turner, W., Reiner, O., and Nekhai, S. (2005). HIV-1 Tat interacts with LIS1 protein. Retrovirology 2, 6.

Haasnoot, J., de Vries, W., Geutjes, E.J., Prins, M., de Haan, P., and Berkhout, B. (2007). The Ebola virus VP35 protein is a suppressor of RNA silencing. PLoS Pathog 3, e86.

Hartitz, M.D., Sunter, G., and Bisaro, D.M. (1999). The tomato golden mosaic virus transactivator (TrAP) is a single-stranded DNA and zinc-binding phosphoprotein with an acidic activation domain. Virology 263, 1-14.

Hartman, A.L., Towner, J.S., and Nichol, S.T. (2004). A C-terminal basic amino acid motif of Zaire ebolavirus VP35 is essential for type I interferon antagonism and displays high identity with the RNA-binding domain of another interferon antagonist, the NS1 protein of influenza A virus. Virology 328, 177-184.

Herrmann, C.H., and Rice, A.P. (1995). Lentivirus Tat proteins specifically associate with a cellular protein kinase, TAK, that hyperphosphorylates the carboxyl-terminal domain of the large subunit of RNA polymerase II: candidate for a Tat cofactor. J Virol 69, 1612-1620.

Huang, J., Wang, F., Argyris, E., Chen, K., Liang, Z., Tian, H., Huang, W., Squires, K., Verlinghieri, G., and Zhang, H. (2007). Cellular microRNAs contribute to HIV-1 latency in resting primary CD4+ T 
lymphocytes. Nat Med 13, 1241-1247.

Isel, C., and Karn, J. (1999). Direct evidence that HIV-1 Tat stimulates RNA polymerase II carboxyl-terminal domain hyperphosphorylation during transcriptional elongation. J Mol Biol 290, 929-941.

Kasschau, K.D., and Carrington, J.C. (1998). A counterdefensive strategy of plant viruses: suppression of posttranscriptional gene silencing. Cell 95, 461-470.

Kasschau, K.D., Cronin, S., and Carrington, J.C. (1997). Genome amplification and long-distance movement functions associated with the central domain of tobacco etch potyvirus helper component-proteinase. Virology 228, 251-262.

Kasschau, K.D., Xie, Z., Allen, E., Llave, C., Chapman, E.J., Krizan, K.A., and Carrington, J.C. (2003). P1/HC-Pro, a viral suppressor of RNA silencing, interferes with Arabidopsis development and miRNA unction. Dev Cell 4, 205-217.

Kiernan, R.E., Vanhulle, C., Schiltz, L., Adam, E., Xiao, H., Maudoux, F., Calomme, C., Burny, A., Nakatani, Y., Jeang, K.T., et al. (1999). HIV-1 tat transcriptional activity is regulated by acetylation. EMBO J 18, 6106-6118.

Kok, K.H., and Jin, D.Y. (2006). Influenza A virus NS1 protein does not suppress RNA interference in mammalian cells. J Gen Virol 87, 2639-2644.

Kubota, K., Tsuda, S., Tamai, A., and Meshi, T. (2003). Tomato mosaic virus replication protein suppresses virus-targeted posttranscriptional gene silencing. J Virol 77, 11016-11026.

Kubota, T., Yokosawa, N., Yokota, S., and Fujii, N. (2002). Association of mumps virus $\mathrm{V}$ protein with RACK1 results in dissociation of STAT-1 from the alpha interferon receptor complex. J Virol 76 , 12676-12682.

Lakatos, L., Szittya, G., Silhavy, D., and Burgyán, J. (2004). Molecular mechanism of RNA silencing suppression mediated by p19 protein of tombusviruses. EMBO J 23, 876-884.

Langland, J.O., and Jacobs, B.L. (2002). The role of the PKRinhibitory genes, $\mathrm{E} 3 \mathrm{~L}$ and $\mathrm{K} 3 \mathrm{~L}$, in determining vaccinia virus host range. Virology 299, 133-141.

Langland, J.O., Kash, J.C., Carter, V., Thomas, M.J., Katze, M.G., and Jacobs, B.L. (2006). Suppression of proinflammatory signal transduction and gene expression by the dual nucleic acid binding domains of the vaccinia virus E3L proteins. J Virol 80, 10083-10095.

Lecellier, C.H., Dunoyer, P., Arar, K., Lehmann-Che, J., Eyquem, S., Himber, C., Saïb, A., and Voinnet, O. (2005). A cellular microRNA mediates antiviral defense in human cells. Science 308, 557-560.

Li, H., Li, W.X., and Ding, S.W. (2002). Induction and suppression of RNA silencing by an animal virus. Science 296, 1319-1321.

Li, W.X., Li, H., Lu, R., Li, F., Dus, M., Atkinson, P., Brydon, E.W., Johnson, K.L., García-Sastre, A., Ball, L.A., et al. (2004). Interferon antagonist proteins of influenza and vaccinia viruses are suppressors of RNA silencing. Proc Natl Acad Sci U S A 101, 1350-1355.

Lin, J., and Cullen, B.R. (2007). Analysis of the interaction of primate retroviruses with the human RNA interference machinery. J Virol 81, 12218-12226.

Liu, L., Grainger, J., Cañizares, M.C., Angell, S.M., and Lomonossoff, G.P. (2004). Cowpea mosaic virus RNA-1 acts as an amplicon whose effects can be counteracted by a RNA-2-encoded suppressor of silencing. Virology 323, 37-48.

Liu, Y., Li, J., Kim, B.O., Pace, B.S., and He, J.J. (2002). HIV-1 Tat protein-mediated transactivation of the HIV-1 long terminal repeat promoter is potentiated by a novel nuclear Tat-interacting protein of 110 kDa, Tip110. J Biol Chem 277, 23854-23863.

Lu, R., Folimonov, A., Shintaku, M., Li, W.X., Falk, B.W., Dawson, W. O., and Ding, S.W. (2004). Three distinct suppressors of RNA silencing encoded by a 20-kb viral RNA genome. Proc Natl Acad Sci U S A 101, 15742-15747.

Moissiard, G., and Voinnet, O. (2004). Viral suppression of RNA silencing in plants. Mol Plant Pathol 5, 71-82.

Mühlberger, E., Weik, M., Volchkov, V.E., Klenk, H.D., and Becker, S. (1999). Comparison of the transcription and replication strategies of marburg virus and Ebola virus by using artificial replication systems. J Virol 73, 2333-2342.

Nath, A., Psooy, K., Martin, C., Knudsen, B., Magnuson, D.S., Haughey, N., and Geiger, J.D. (1996). Identification of a human immunodeficiency virus type 1 Tat epitope that is neuroexcitatory and neurotoxic. J Virol 70, 1475-1480.

Olivieri, D., Sykora, M.M., Sachidanandam, R., Mechtler, K., and Brennecke, J. (2010). An in vivo RNAi assay identifies major genetic and cellular requirements for primary piRNA biogenesis in Drosophila. EMBO J 29, 3301-3317.

Otsuka, M., Jing, Q., Georgel, P., New, L., Chen, J., Mols, J., Kang, Y. J., Jiang, Z., Du, X., Cook, R., et al. (2007). Hypersusceptibility to vesicular stomatitis virus infection in Dicer1-deficient mice is due to impaired miR24 and miR93 expression. Immunity 27, 123-134.

Pfeffer, S., Dunoyer, P., Heim, F., Richards, K.E., Jonard, G., and Ziegler-Graff, V. (2002). P0 of beet Western yellows virus is a suppressor of posttranscriptional gene silencing. J Virol 76, 6815-6824.

Pfeffer, S., Sewer, A., Lagos-Quintana, M., Sheridan, R., Sander, C., Grässer, F.A., van Dyk, L.F., Ho, C.K., Shuman, S., Chien, M., et al. (2005). Identification of microRNAs of the herpesvirus family. Nat Methods 2, 269-276.

Pruss, G., Ge, X., Shi, X.M., Carrington, J.C., and Bowman Vance, V. (1997). Plant viral synergism: the potyviral genome encodes a broad-range pathogenicity enhancer that transactivates replication of heterologous viruses. Plant Cell 9, 859-868.

Qu, F., Ren, T., and Morris, T.J. (2003). The coat protein of turnip crinkle virus suppresses posttranscriptional gene silencing at an early initiation step. J Virol 77, 511-522.

Reed, J.C., Kasschau, K.D., Prokhnevsky, A.I., Gopinath, K., Pogue, G.P., Carrington, J.C., and Dolja, V.V. (2003). Suppressor of RNA silencing encoded by Beet yellows virus. Virology 306, 203-209.

Reyes, C.A., De Francesco, A., Pena, E.J., Costa, N., Plata, M.I., Sendin, L., Castagnaro, A.P., and Garcia, M.L. (2011). Resistance to Citrus psorosis virus in transgenic sweet orange plants is triggered by coat protein-RNA silencing. J Biotechnol 151, 151-158.

Ruiz, M.T., Voinnet, O., and Baulcombe, D.C. (1998). Initiation and maintenance of virus-induced gene silencing. Plant Cell 10, 937-946.

Rusnati, M., and Presta, M. (2002). HIV-1 Tat protein and endothelium: from protein/cell interaction to AIDS-associated pathologies. Angiogenesis 5, 141-151.

Saunders, L.R., and Barber, G.N. (2003). The dsRNA binding protein family: critical roles, diverse cellular functions. FASEB J 17, 961-983.

Silhavy, D., Molnár, A., Lucioli, A., Szittya, G., Hornyik, C., Tavazza, 
M., and Burgyán, J. (2002). A viral protein suppresses RNA silencing and binds silencing-generated, 21- to 25-nucleotide double-stranded RNAs. EMBO J 21, 3070-3080.

Song, L., Liu, H., Gao, S., Jiang, W., and Huang, W. (2010). Cellular microRNAs inhibit replication of the H1N1 influenza $A$ virus in infected cells. J Virol 84, 8849-8860.

Takeda, A., Sugiyama, K., Nagano, H., Mori, M., Kaido, M., Mise, K., Tsuda, S., and Okuno, T. (2002). Identification of a novel RNA silencing suppressor, NSs protein of Tomato spotted wilt virus. FEBS Lett 532, 75-79.

Thomas, C.L., Leh, V., Lederer, C., and Maule, A.J. (2003). Turnip crinkle virus coat protein mediates suppression of RNA silencing in Nicotiana benthamiana. Virology 306, 33-41.

van Rij, R.P. (2008). Virus meets RNAi. Symposium on antiviral applications of RNA interference. EMBO Rep 9, 725-729.

Van Wezel, R., Liu, H., Wu, Z., Stanley, J., and Hong, Y. (2003). Contribution of the zinc finger to zinc and DNA binding by a suppressor of posttranscriptional gene silencing. J Virol 77, 696-700.

van, W.R., Dong, X., Liu, H., Tien, P., Stanley, J., and Hong, Y. (2002). Mutation of three cysteine residues in Tomato yellow leaf curl virusChina C2 protein causes dysfunction in pathogenesis and posttranscriptional gene-silencing suppression. Mol Plant Microbe Interact 15, 203-208.

Vance, V.B. (1991). Replication of potato virus X RNA is altered in coinfections with potato virus Y. Virology 182, 486-494.

Voinnet, O., Lederer, C., and Baulcombe, D.C. (2000). A viral movement protein prevents spread of the gene silencing signal in Nicotiana benthamiana. Cell 103, 157-167.

Voinnet, O., Pinto, Y.M., and Baulcombe, D.C. (1999). Suppression of gene silencing: a general strategy used by diverse DNA and RNA viruses of plants. Proc Natl Acad Sci U S A 96, 14147-14152.

Wang, Y., Kato, N., Jazag, A., Dharel, N., Otsuka, M., Taniguchi, H., Kawabe, T., and Omata, M. (2006). Hepatitis $C$ virus core protein is a potent inhibitor of RNA silencing-based antiviral response. Gastroenterology 130, 883-892.

Yang, X., Gold, M.O., Tang, D.N., Lewis, D.E., Aguilar-Cordova, E., Rice, A.P., and Herrmann, C.H. (1997). TAK, an HIV Tatassociated kinase, is a member of the cyclin-dependent family of protein kinases and is induced by activation of peripheral blood lymphocytes and differentiation of promonocytic cell lines. Proc Natl Acad Sci U S A 94, 12331-12336.

Yelina, N.E., Savenkov, E.I., Solovyev, A.G., Morozov, S.Y., and Valkonen, J.P. (2002). Long-distance movement, virulence, and RNA silencing suppression controlled by a single protein in hordeiand potyviruses: complementary functions between virus families. J Virol 76, 12981-12991.

Zamore, P.D., Tuschl, T., Sharp, P.A., and Bartel, D.P. (2000). RNAi: double-stranded RNA directs the ATP-dependent cleavage of mRNA at 21 to 23 nucleotide intervals. Cell 101, 25-33. 